\title{
Multi-objective based Optimal Network Reconfiguration using Crow Search Algorithm
}

\author{
Surender Reddy Salkuti \\ Department of Railroad and Electrical Engineering, Woosong University, Daejeon, South Korea
}

\begin{abstract}
This paper presents an optimal network reconfiguration (ONR)/feeder reconfiguration (FRC) approach by considering the total operating cost and system power losses minimizations as objectives. The ONR/FRC is a feasible approach for the enhancement of system performance in distribution systems (DSs). FRC alters the topological structure of feeders by changing the close/open status of the tie and sectionalizing switches in the system. Apart from the power received from the main grid, this paper considers the power from distributed generation (DG) sources such as wind energy generators (WEGs), solar photovoltaic (PV) units, and battery energy storage (BES) units. The proposed multi-objective-based ONR/FRC problem has been solved by using the multi-objective crow search algorithm (MO-CSA). The proposed methodology has been implemented on two (14 bus and 17 bus) distribution systems with three feeders.
\end{abstract}

Keywords-Battery storage; distributed generation; evolutionary algorithms; network reconfiguration; renewable energy; uncertainty

\section{NOMENCLATURE}

$S_{S S}$

Apparent power flowing through the substation transformer

$S_{S S}^{\max }$

Maximum apparent power flowing through the

substation transformer

$I_{f} \quad$ Current magnitude of feeder

$I_{f}^{\max } \quad$ Maximum current magnitude of feeder

$v_{r} \quad$ Rated wind speed

$P_{B}^{C h} \quad$ Battery charging power

$P_{B}^{\text {Disch }} \quad$ Battery discharging power

$P_{T}^{\text {Demand }}$ Total power demand in the system

$P_{T}^{\text {loss }} \quad$ Total power losses in the system

$v_{c o} \quad$ Cut-out wind speed

$P_{W}^{r} \quad$ Rated power of wind turbine (WT)

$P_{P V}^{r} \quad$ Rated solar PV power output

$G_{c} \quad$ Certain solar irradiation (say $150 \mathrm{~W} / \mathrm{m}^{2}$ )

$v_{c i} \quad$ Cut-in wind speed

$G_{\text {std }} \quad$ Solar irradiation at standard test environment
$\left.\mathrm{W} / \mathrm{m}^{2}\right)$

$C_{i} \quad$ Cost of power from the $\mathrm{i}^{\text {th }}$ feeder (from the main grid)

$P_{i} \quad$ Power output from the $\mathrm{i}^{\text {th }}$ feeder (from the main grid)

$C_{W j} \quad$ Cost of power from the $\mathrm{j}^{\text {th }}$ wind energy generator (WEG)

$P_{W j} \quad$ Power output from the $\mathrm{j}^{\text {th }}$ WEG

$C_{P V k} \quad$ Cost of power from the $\mathrm{k}^{\text {th }}$ solar PV unit

$P_{P V k} \quad$ Power output from the $\mathrm{k}^{\text {th }}$ solar PV unit

$C_{B b} \quad$ Cost of power from the $\mathrm{b}^{\text {th }}$ battery storage unit

$P_{B b} \quad$ Power output from the $\mathrm{b}^{\text {th }}$ battery storage unit

$N_{F} \quad$ Number of feeders

$N_{W} \quad$ Number of WEGs

$N_{P V} \quad$ Number of solar PV units

$N_{B} \quad$ Number of battery storage units

$N_{\text {Bus }} \quad$ Number of buses

\section{INTRODUCTION}

Generally, the power losses in the distribution network are significantly high compared to those in the transmission system due to the high resistance/reactance $(\mathrm{R} / \mathrm{X})$ ratio. Distribution systems (DSs) operate at high currents and low voltages which lead to high power loss and poor voltage profile. Another reason is due to the radial topology of distribution systems when compared to transmission systems [1]. The requirement of enhancing the overall efficiency of power delivery has forced the power utilities to reduce the losses at the distribution level. Many arrangements can be worked out to reduce these losses such as feeder reconfiguration (FRC)/optimal network reconfiguration (ONR), shunt capacitor switchings, etc. The FRC or ONR is the process of changing the topological structure of feeders by varying the positions of tie/sectional (generally open/closed) switches [2]. For a fixed network configuration of a distribution system with varying load conditions, it is observed that the power losses are not optimum. FRC/ONR has several advantages, such as managing network overloading, voltage profile improvement, optimization of system power losses and system operating cost, restoration of service during feeder faults, and system maintenance through 
planned outages. Therefore, there is a pressing requirement for the ONR/FRC to optimize system power losses and relieve network overloading. Recently, the electricity demand is rapidly increasing due to population exploitation and urbanization. Conventional electricity generation utilizes fossil fuels. But, the overutilization of fossil fuels causes depletion of fuels and affects the environment [3]. To overcome these issues, this work utilizes renewable energy resources (RERs), such as wind energy generators (WEGs), solar PV units, and battery energy storage (BES) units.

An ONR approach by considering the power loss minimization and improvement of voltage profile has been proposed in [4]. In [5] proposes the ONR approach by optimally allocating distributed generation (DG) and soft open points simultaneously. In [6] proposes an ONR and phase balancing methodology for minimizing the power losses in conventional distribution systems (DSs) and microgrids (MGs) using the particle swarm optimization (PSO) algorithm. Optimal DG allocation and ONR have been presented in [7] to improve the loss profile and voltage stability of the radial distribution systems (RDSs) considering the DGs and probabilistic loads which are operated at varying power factors. An optimal multi-criterion of FRCs with solar PV and wind-based RERs using the weight factor approach considering the reliability has been proposed in [8]. An optimal dispatching and control of all hybrid MG sources such as conventional generators, RERs, demand-manageable loads, and energy storage system have been presented in [9]. In [10] proposes an ONR of DSs under a multi-objective optimization (MOO) model to minimize power losses and to enhance the reliability of DSs. A MOO based on ONR in parallel with renewable DGs allocation and sizing for optimizing the active power loss, annual operation costs (maintenance, installation, and active power loss costs), and emissions have been proposed in [11]. A mixed PSO technique for the minimization of active power loss and the enhancement of voltage profile in the DS has been proposed in [12]. A multiscale formation generation problems are introduced and solved as the generalizations in 13].

From the above literature review, it can be observed that there is a pressing requirement for simultaneously optimizing the total operating cost (TOC) and power loss minimization objectives in the RDS using the ONR/FRC. Optimal FRC alters the feeder topological structure by changing the close/open status of the tie switches and sectionalizing in the system [14, 15]. Apart from the power received from the main grid, this paper considers the power from the DG units such as wind energy generators (WEGs), solar PV units, and battery energy storage (BES) units. The proposed multi-objectivebased ONR problem has been solved by using the multiobjective crow search algorithm (MO-CSA). The proposed methodology has been implemented on 14 bus and 17 bus distribution systems.

The paper presented is as follows: Section II explains the mathematical modeling of DG sources, such as wind, solar $\mathrm{PV}$, and battery storage. In section III multi-objective-based problem formulation with system power losses and operating cost objectives has been described. Section IV presents the description of the multi-objective crow search algorithm (MO-
CSA). The performance of the proposed model on 14 bus and 17 bus DSs is presented in the results and discussion in Section V. Section VI concludes the paper.

\section{Modeling OF DistRIBUTED GENERATION (DG) UNITS}

This section presents the modeling of RERs based DG sources, i.e., WEGs, solar PV units, and BES units.

\section{A. Modeling of Wind Power}

In the WEG, the kinetic energy (KE) of wind is going to be converted into electrical power. The power output from a wind turbine $\left(P_{W}\right)$ depends on variations in wind speed $(v)$, and it can be expressed as [16],

$$
P_{W}=\left\{\begin{array}{lr}
0 & \text { if } v \leq v_{c i} \text { and } v \geq v_{c o} \\
a v^{3}-b P_{W}^{r} & \text { if } v_{c i} \leq v<v_{r} \\
P_{W}^{r} & \text { if } v_{r} \leq v<v_{c o}
\end{array}\right.
$$

Where $a=\frac{P_{W}^{r}}{v_{r}^{3}-v_{c i}^{3}}$ and $b=\frac{v_{c i}^{3}}{v_{r}^{3}-v_{c i}^{3}}$. Generally, the stochastic nature of wind speed $(v)$ is modeled using the Weibull probability distribution function (PDF). From the knowledge of wind speed distribution, the wind power $\left(P_{W}\right)$ is derived and it is depicted in Fig. 1.

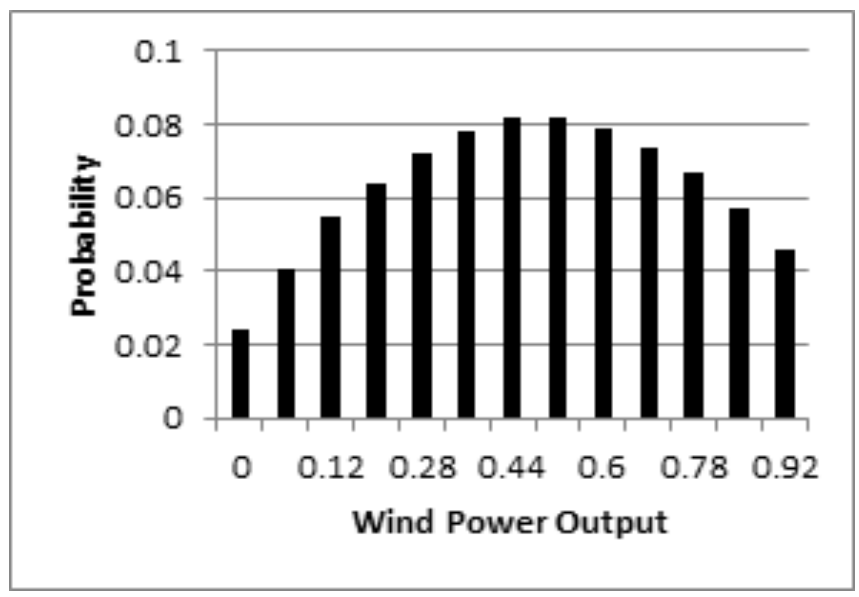

Fig. 1. Wind Power Distribution.

The uncertain nature of wind speed $(v)$ can be expressed as [17],

$f(v)=\left(\frac{k}{c}\right)\left(\frac{v}{c}\right)^{k-1} e^{-\left(\frac{v}{c}\right)^{k}} \quad$ for $0 \leq v \leq \infty$

The uncertain nature of wind power $\left(P_{W}\right)$ using Weibull PDF can be expressed as [17],

$$
\begin{aligned}
f\left(P_{W}\right)=\frac{k\left(v_{r}-v_{c i}\right)}{c^{k} P_{W}}\left(v_{c i}\right. & \\
+ & \frac{P_{W}}{P_{W}^{r}}\left(v_{r}\right. \\
& \left.\left.-v_{c i}\right)^{(k-1)}\right) e^{-\left(\frac{v_{c i}+\frac{P_{W}}{P_{W}^{r}}\left(v_{r}-v_{c i}\right)}{c}\right)^{k}}
\end{aligned}
$$




\section{B. Modeling of Solar PV Power}

The amount of power output from solar PV unit $\left(P_{P V}\right)$ depends on the solar irradiation (G), and it can be expressed as [18],

$P_{P V}=\left\{\begin{array}{lr}\frac{G^{2} P_{P V}^{r}}{G_{s t d} G_{c}} & \text { for } 0 \leq G<G_{c} \\ G P_{P V}^{r} & \text { for } G_{c} \leq G<G_{s t d} \\ G_{s t d} & \text { for } G \geq G_{\text {std }}\end{array}\right.$

In this paper, the uncertainty modeling of the solar PV unit is modeled by using the Beta distribution function, and its value is in the interval $[0,1]$. It is modeled using,

$f(G)=\frac{\Gamma(\alpha+\beta)}{\Gamma(\alpha) \Gamma(\beta)} G^{(\alpha-1)}(1-G)^{(\beta-1)}$

The parameters $\alpha$ and $\beta$ are calculated by using mean $(\mu)$ and variance $(\sigma)$ of solar irradiance data, and they are calculated using,

$\beta=(1-\mu)\left[\frac{\mu(1+\mu)}{\sigma^{2}}-1\right]$

$\alpha=\left(\frac{\mu \beta}{1-\mu}\right)$

\section{Modeling of Battery Energy Storage (BES)}

The BES unit provides the flexibility to handle the uncertainty of wind and solar PV units. The operational constraints of battery storage are presented next:

The battery storage power $\left(P_{B}\right)$ is limited by [19],

$-P_{B}^{\max } \leq P_{B} \leq P_{B}^{\max }$

Battery power is positive during the charging mode and negative during the discharging mode. The state of charge (SoC) of battery at time $t$ is expressed as [20],

$S o C_{t}=S o C_{t-1}+\left(\frac{P_{B}}{P_{B}^{\max }}\right)$

The limit on SoC presents the excessive discharging and charging of the battery, and it can be expressed as,

$\operatorname{SoC}^{\min } \leq \mathrm{SoC}_{t} \leq \operatorname{SoC}^{\max }$

Where $S o C^{\min }$ and $S o C^{\max }$ are 0.2 and 0.9 , respectively.

\section{Problem Formulation: Mathematical Modeling OF ONR/FRC}

Optimal network reconfiguration (ONR) is an important tool to operate the distribution system (DS) at a minimum operating cost and/or minimum system power losses and for the enhancement of system security/reliability [21]. The ONR is a complicated problem as they have several candidate switching (both sectional and tie switches) combinations, which makes it a discrete optimization problem [22]. In this work, two important technical objectives, i.e., total operating cost (TOC) and system power loss minimizations are considered.

\section{A. Objective 1: Total Operating Cost (TOC) Minimization}

The TOC objective includes the cost due to power from the grid (i.e., the power to the feeders), cost due to wind power, solar PV power, and BES units. This TOC objective can be formulated as [23],

Minimize,

$$
\begin{aligned}
\text { TOC }=\sum_{i=1}^{N_{F}}\left(C_{i} \times\right. & \left.P_{i}\right)+\sum_{j=1}^{N_{W}}\left(C_{W j} \times P_{W j}\right) \\
& +\sum_{\substack{k=1 \\
N_{P V}}}^{N_{B}}\left(C_{P V k} \times P_{P V k}\right) \\
& +\sum_{b=1}\left(C_{B b} \times P_{B b}\right)
\end{aligned}
$$

\section{B. Objective 2: System Power Losses Minimization}

Usually, the distribution networks are radial to reduce the protection complexities, and they have a high $\mathrm{R} / \mathrm{X}$ ratio and hence they have high active power loss [24]. It is very important to reduce the system power losses for increasing the operational efficacy of the system. Fig. 2 depicts the single line diagram (SLD) of the radial distribution system (RDS) with one main feeder and $N_{B u s}$ number of buses [25]. The formulation of this objective can be formulated next:

The active power losses obtained in the section of line between the bus $\mathrm{j}$ and bus $(\mathrm{j}+1)$, and can be expressed by [26],

$P_{(j, j+1)}^{\text {loss }}=\left(\frac{P_{(j, j+1)}^{2}+Q_{(j, j+1)}^{2}}{\left|V_{j}\right|^{2}}\right) R_{(j, j+1)}$

The reactive power losses obtained in the section of line between the bus $\mathrm{j}$ and bus ( $\mathrm{j}+1)$, and can be expressed by [27],

$Q_{(j, j+1)}^{l o s s}=\left(\frac{P_{(j, j+1)}^{2}+Q_{(j, j+1)}^{2}}{\left|V_{j}\right|^{2}}\right) X_{(j, j+1)}$

Total active power losses $\left(P_{T}^{\text {loss }}\right)$ occurred in the RDS can be expressed as [28],

$P_{T}^{\text {loss }}=\sum_{j=0}^{N_{B u s}-1}\left(\frac{P_{(j, j+1)}^{2}+Q_{(j, j+1)}^{2}}{\left|V_{j}\right|^{2}}\right) R_{(j, j+1)}$

The system power loss minimization objective can be formulated as [29],

minimize $\quad P_{T}^{\text {loss }}$

To perform the ONR/FRC problem in DSs, the system needs to satisfy certain equality and inequality constraints. The mathematical representation of those constraints is presented in the following subsection. 


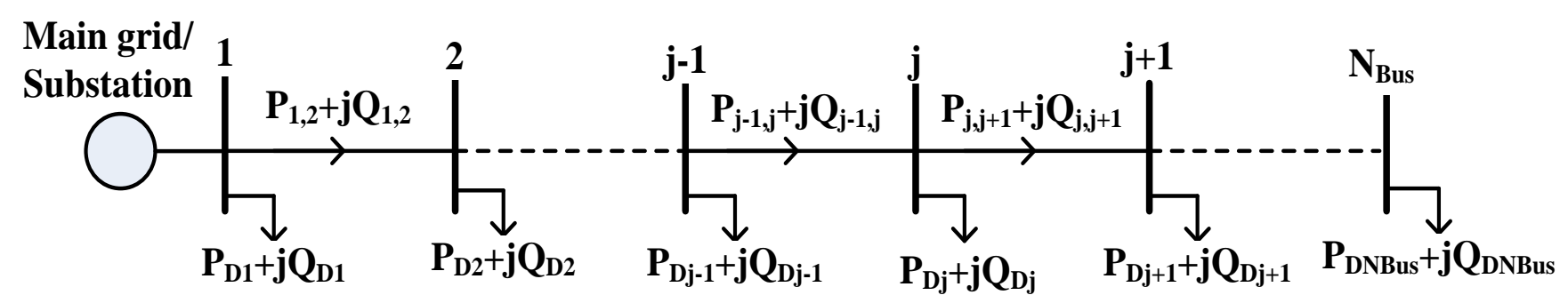

Fig. 2. Single Line Diagram (SLD) of the Radial Distribution System (RDS) with $N_{B u s}$ Number of Buses.

\section{Constraints}

The power balance equation states that the total active power generation from WEGs, solar PV units, power from main grid/substation, and batteries discharging power must be equal to total active power demand, total power losses, and battery charging power [30]. This power flow constraint can be expressed as,

$$
\begin{aligned}
\sum_{i=1}^{N_{F}} P_{i}+\sum_{j=1}^{N_{W}} P_{W j} & +\sum_{k=1}^{N_{P V}} P_{P V k}+\sum_{b=1}^{N_{B}} P_{B b}^{\text {Disch }} \\
& =P_{T}^{\text {Demand }}+P_{T}^{\text {loss }}+\sum_{b=1}^{N_{B}} P_{B b}^{C h}
\end{aligned}
$$

The bus voltage at each bus must be within the minimum and maximum bus voltage limits, and this constraint can be expressed as [31],

$V_{b}^{\min } \leq V_{b} \leq V_{b}^{\max } \quad b=1,2,3, \ldots, N_{\text {Bus }}$

Power in each feeder is limited by [32],

$P_{i} \leq P_{i}^{\max } \quad i=1,2,3, \ldots, N_{F}$

Power in each WEG is limited by,

$P_{W j} \leq P_{W j}^{\max } \quad j=1,2,3, \ldots, N_{W}$

Power in each solar PV unit is limited by [32],

$P_{P V k} \leq P_{P V k}^{\max } \quad k=1,2,3, \ldots, N_{P V}$

Thermal limits of substation/main grid are limited by [33],

$$
S_{s s} \leq S_{s s}^{\max }
$$

Thermal limits of feeders are limited by,

$$
I_{f} \leq I_{f}^{\max }
$$

In this paper, the single objective-based ONR/FRC problem has been solved by using the crow search algorithm (CSA) and the MOO-based ONR/FRC problem has been solved by using the MO-CSA.

\section{Multi-Objective Crow Search Algorithm (MO- CSA)}

The crow search algorithm (CSA) is a population-based nature-inspired technique that mimics the crow's behavior and social interaction. Crows live in flock/group and their foods in some hiding places. These intelligent crows memorize these places and retrieve the hidden foods even after several months. The crows in the flock represent the solution in the population of size $N$. The following steps are involved during the implementation of CSA [34].

\section{A. Position Initialization}

Let $S_{i}^{t}$ represents the position of each crow $i$ in $t^{\text {th }}$ iteration and it can be expressed as,

$S_{i}^{t}=\left[S_{i, 1}^{t}, S_{i, 2}^{t}, S_{i, 3}^{t}, \ldots \ldots, S_{i, n}^{t}\right]$

Where $n$ is the problem dimension.

\section{B. Memory Initialization}

Let $m_{i}^{t}$ represents the memory of each crow $i$ in $t^{t h}$ iteration and it can be expressed as [34],

$m_{i}^{t}=\left[m_{i, 1}^{t}, m_{i, 2}^{t}, m_{i, 3}^{t}, \ldots ., m_{i, n}^{t}\right]$

Each solution in the population is evaluated by calculating the fitness by using the objective function/fitness function $f\left(S_{i}^{(t+1)}\right)$.

\section{Position Update}

Suppose crow $i$ follows crow $j$ and the crow $j$ doesn't watch crow $i$, then crow $i$ will discover food's hiding place of crow $j$. In this case, the position of crow $i$ is updated by using [34],

$S_{i}^{t+1}=S_{i}^{t}+\left[r_{i} f l_{i}^{t}\left(m_{j}^{t}-S\right)\right]$

Where $S_{i}^{t+1}$ is the new/updated position of crow $i$ at $(t+1)^{t h}$ iteration, $r$ is a random number between 0 and 1 , and $f l_{i}$ is flight length. Suppose crow $i$ follows crow $j$ and the crow $j$ knows that crow $i$ is watching it, then crow $j$ moves randomly to fool crow $i$. This process can be expressed by using [35],

$S_{i}^{t+1}=\left\{\begin{array}{lc}S_{i}^{t}+\left[r_{i} f l_{i}^{t}\left(m_{j}^{t}-S_{i}^{t}\right)\right] & \text { if } r_{j} \geq P_{c}^{t} \\ \text { A random position } & \text { Otherwise }\end{array}\right.$

\section{Memory Update}

Each crow updates its memory based on its fitness value. The fitness of new crow's position (i.e., $f\left(S_{i}^{(t+1)}\right)$ ) is better than the current memory's value (i.e., $\left.f\left(m_{i}^{t}\right)\right)$ then it will update its memory $\left(m_{i}^{t+1}\right)$ to $S_{i}^{t+1}$, otherwise, it will not change its memory $\left(m_{i}^{t+1}=m_{i}^{t}\right)$. This can be expressed as [36], 
$m_{i}^{t+1}=\left\{\begin{array}{lr}S_{i}^{t+1} & \text { if } f\left(S_{i}^{t+1}\right)>f\left(m_{i}^{t}\right) \\ m_{i}^{t} & \text { Otherwise }\end{array}\right.$

For implementing the MO-CSA, an empty external Pareto set is generated with the maximum size of $\bar{N}$. In each iteration, the best non-dominated solutions of the current flock are copied to the external Pareto set $(\bar{N})$. If the size of the external Pareto set exceeds $\bar{N}$, then use hierarchical clustering technique to limit the external population size to $\bar{N}$. Update the position and memory of the combined population/flock $(\mathrm{N}+\bar{N})$ using the equations (26) and (27), respectively. This process is repeated until the termination criteria are satisfied. The members of the Pareto optimal set offer the required Pareto optimal front. The final best-compromised solution is obtained by using the fuzzy-min-max approach. The flow chart of MO-CSA has been depicted in Fig. 3.

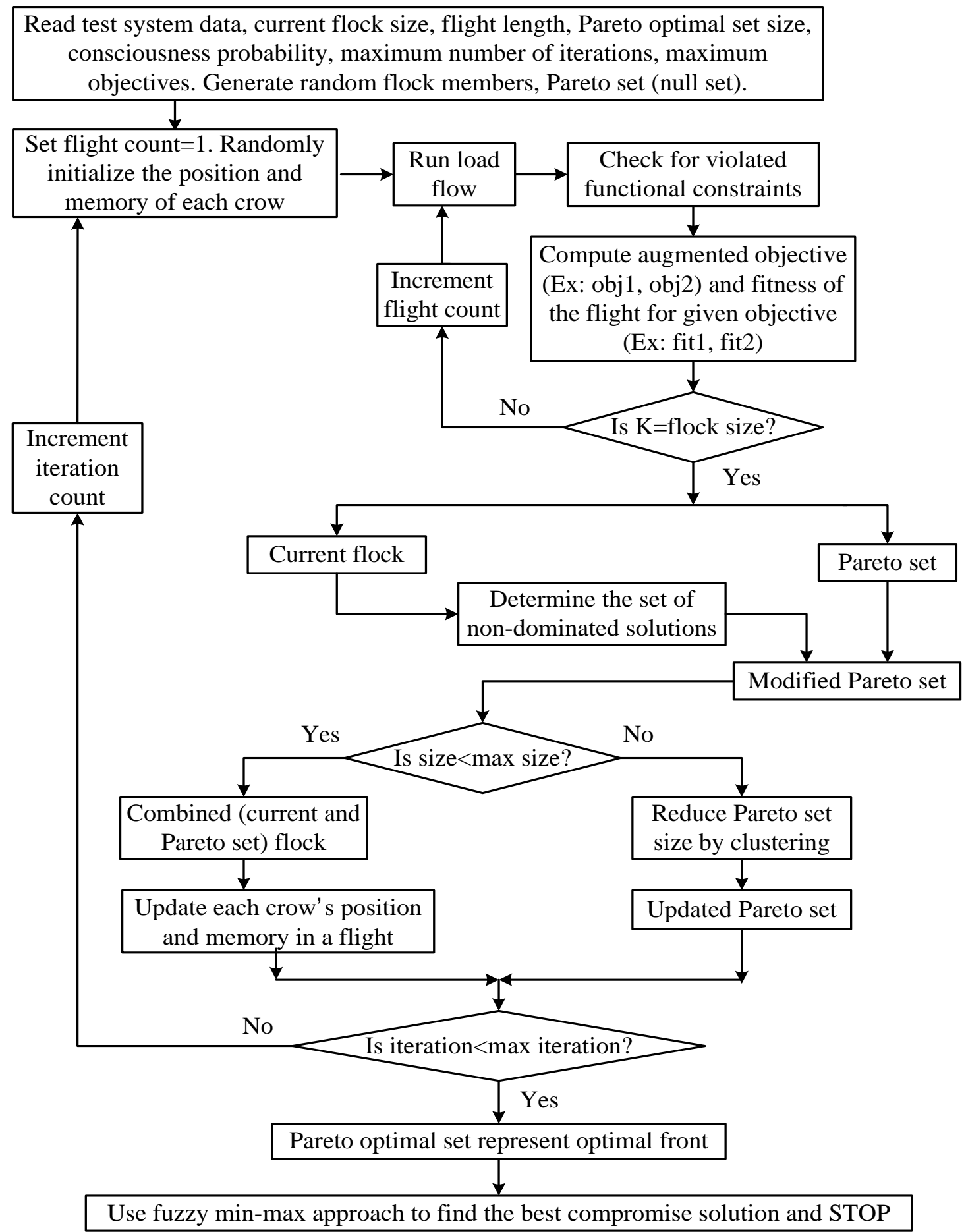

Fig. 3. Flow Chart of MO-CSA. 


\section{RESULTS AND DISCUSSION}

As mentioned earlier, in this paper the ONR/FRC problem has been implemented on 14 bus and 17 bus DSs. In this work, the single objective-based ONR/FRC problem has been solved using the CSA and the MOO-based ONR/FRC problem has been solved by using MO-CSA. All the optimization programs are codes in MATLAB R2018a software on a personal computer with a 64 bit, $2.5 \mathrm{GHz}$, Intel Core-i7 processor, and 8 GB RAM. Parameters related to WEG are: cut-in wind speed is $3 \mathrm{~m} / \mathrm{s}$, rated wind speed is $12 \mathrm{~m} / \mathrm{s}$, cut-out wind speed is $25 \mathrm{~m} / \mathrm{s}$, and rated power of WEG is $2 \mathrm{MW}$. The rated capacities of solar PV units and BES units are $3 \mathrm{MW}$ and 1 MW, respectively.

\section{A. Simulation Results on 14 Bus Distribution System}

The 14 bus distribution system consists of 16 branches, 3 feeders, and 3 tie-switches. The active and reactive power demands are 28.7 MW and 17.3 MVAr, respectively. In this test system, one WEG is placed at bus 11 , one solar PV unit is placed at bus 6 , and one BES unit is placed at bus 12. Fig. 4 depicts the SLD of 14 bus distribution system.

Table I presents the power outputs and objective function values for 14 bus system. When the TOC minimization objective is optimized independently, then the obtained optimum TOC is $668.23 \$ / \mathrm{h}$ and the corresponding power loss is $0.63 \mathrm{MW}$. When the system power loss minimization objective is optimized independently, then the optimum power loss obtained is $0.45 \mathrm{MW}$, and the corresponding TOC is $715.01 \$ / \mathrm{h}$. From this analysis, it can be observed that when one objective is optimized independently then the other objective has deviated from the optimum. Therefore, there is a pressing requirement for simultaneously optimizing the TOC and system power losses.

In this paper, the MO-CSA is used for solving the proposed MOO problem. When the TOC and system power loss minimization objectives are optimized simultaneously, then the obtained Pareto optimal front/set has been depicted in Fig. 5. The obtained best-compromised solution using the fuzzy min-max approach has the TOC of $683.50 \$ / \mathrm{h}$ and system power losses of $0.50 \mathrm{MW}$. The opened lines after the ONR/FRC are line 6 (connected between buses 2 and 6), line 9 (connected between buses 3 and 8), and line 10 (connected between buses 8 and 12). Fig. 6 depicts the SLD of 14 bus DS after the ONR/FRC.

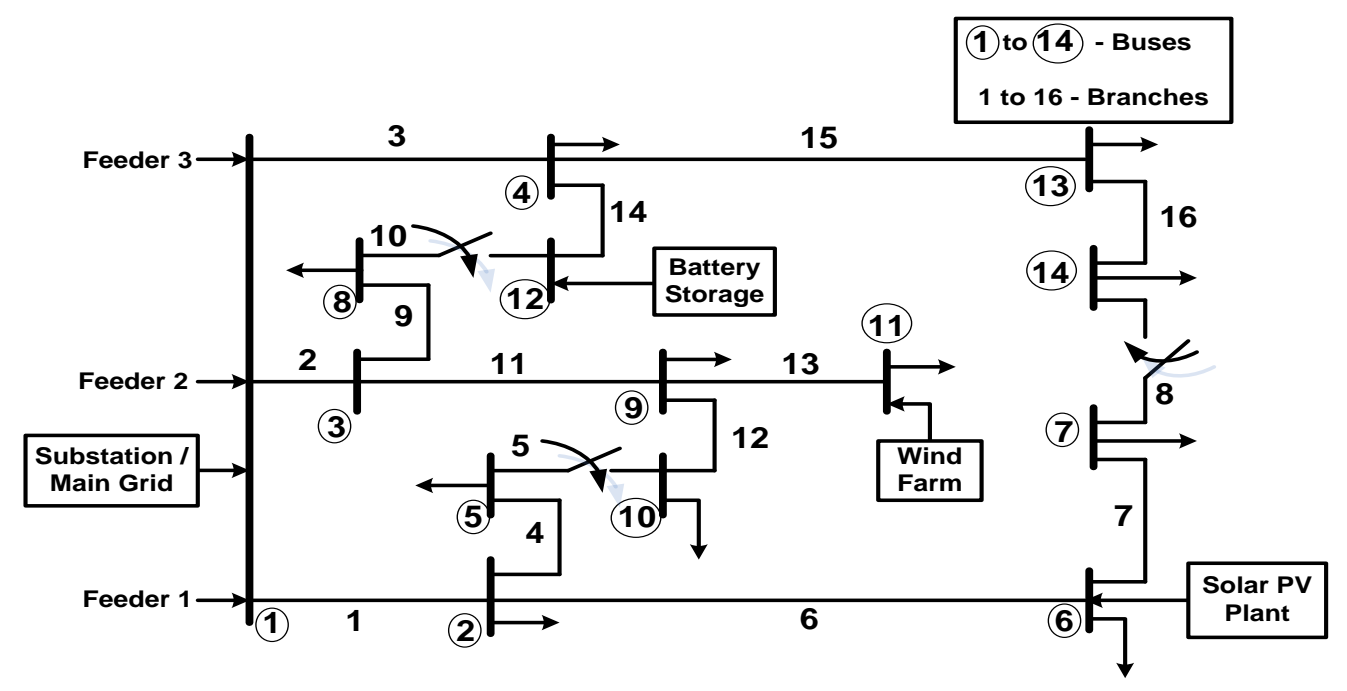

Fig. 4. SLD of 14 Bus Distribution System.

TABLE I. OBJECTIVE FUNCTION VALUES FOR 14 BUS DS

\begin{tabular}{|l|l|l|l|}
\hline \multirow{2}{*}{ Power outputs and objective function values } & \multicolumn{2}{|l|}{ Single objective-based ONR } & MOO based ONR \\
\cline { 2 - 4 } & TOC Minimization & Power loss Minimization & TOC and Power loss minimization \\
\hline Power output from feeders (MW) & 24.07 & 24.35 & 24.60 \\
\hline Power output from WEGs (MW) & 1.92 & 1.85 & 1.89 \\
\hline Power output from solar PV unit (MW) & 1.79 & 1.64 & 1.80 \\
\hline Power output from BES unit (MW) & 0.92 & 0.86 & 0.91 \\
\hline Total operating cost (TOC) (\$/h) & $\mathbf{6 6 8 . 2 3}$ & 715.01 & $\mathbf{6 8 3 . 5 0}$ \\
\hline System power losses (MW) & 0.63 & $\mathbf{0 . 4 5}$ & $\mathbf{0 . 5 0}$ \\
\hline
\end{tabular}




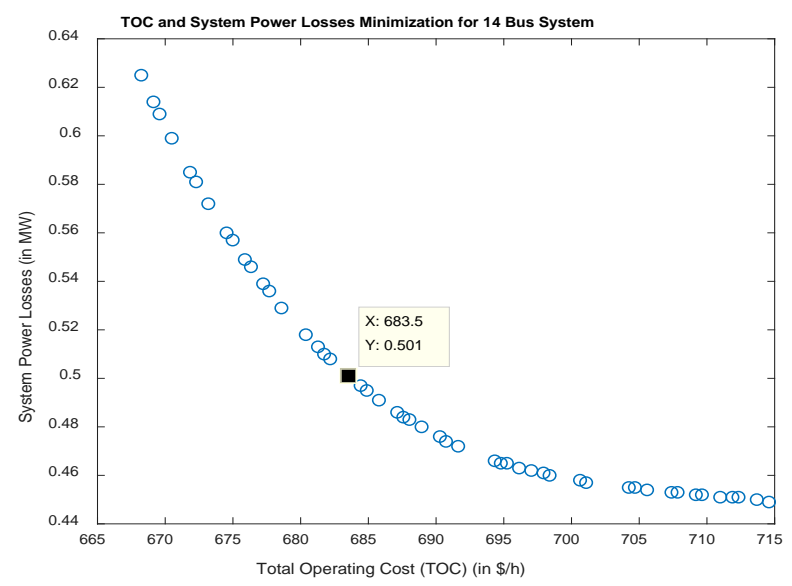

Fig. 5. Pareto Optimal Front of TOC and System Power Losses for 14 bus System.

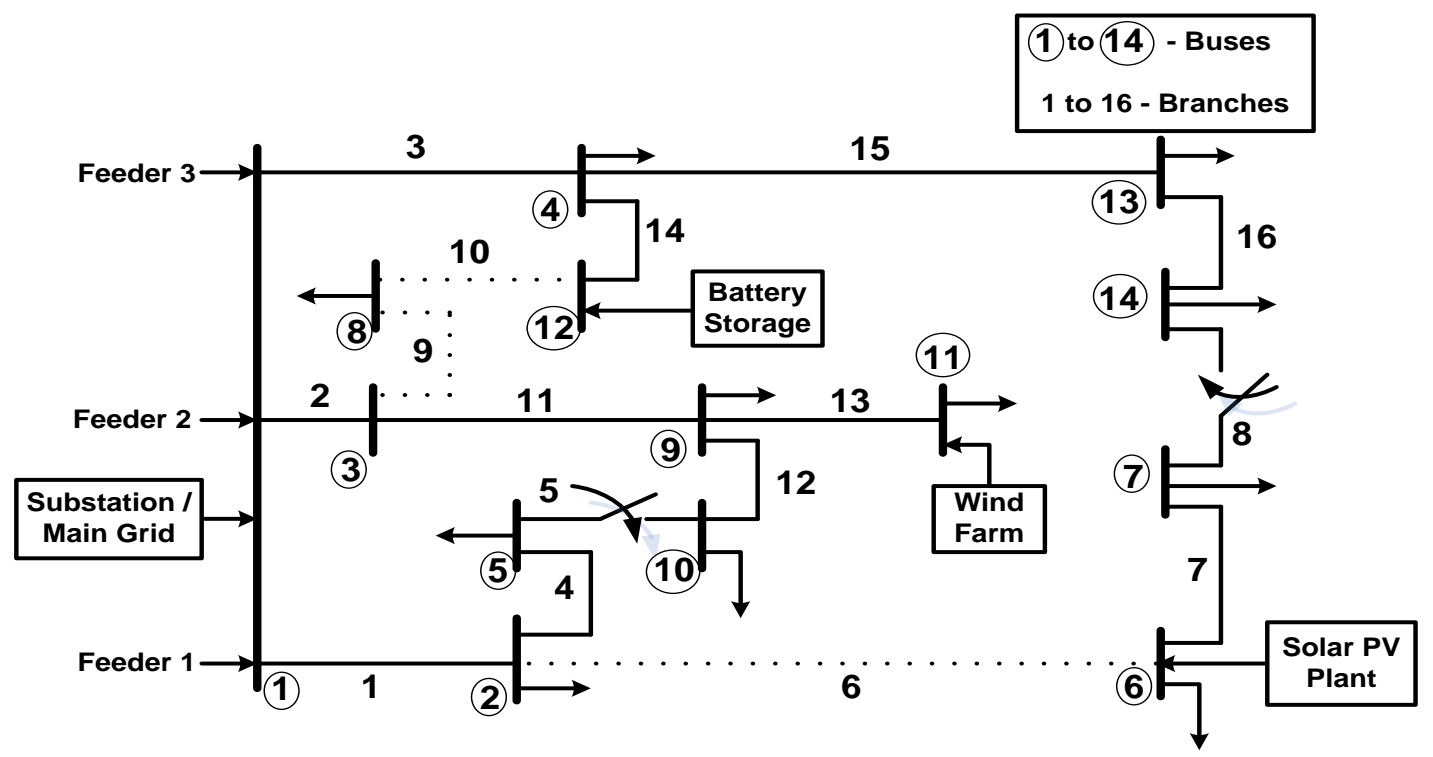

Fig. 6. SLD of 14 Bus DS after Optimal Network Reconfiguration (ONR) / FRC.

\section{B. Simulation Results on 17 Bus Distribution System}

The 17 bus DS consists of 17 buses, 19 branches, 3 feeders, and 3 tie-switches. Three transformers of rating $115 \mathrm{kV} / 13.2 \mathrm{kV}$ of $\Delta-Y_{g}$ connection with the leakage impedance of $(0.01+\mathrm{j} 0.05)$ p.u. are connected at the beginning of 3 feeders. The active and reactive power demands of 17 bus system are 86.10 MW and 51.90 MVAr, respectively. The SLD of 17 bus DS has been depicted in Fig. 7.

Table II presents the power outputs and objective function values for the 17 bus system. When the TOC minimization objective is optimized independently, then the obtained optimum TOC is $1862.06 \$ / \mathrm{h}$ and the corresponding power loss is $2.76 \mathrm{MW}$. When the system power loss minimization objective is optimized independently, then the optimum power loss obtained is $1.95 \mathrm{MW}$, and the corresponding TOC is
1903.12 \$/h. From this analysis, it can be observed that when one objective is optimized independently then the other objective has deviated from the optimum. Therefore, there is a pressing requirement for simultaneously optimizing the TOC and system power loss objectives.

In this paper, the MO-CSA is used for solving the proposed MOO problem. When the TOC and system power losses are optimized simultaneously, then the obtained Pareto optimal front has been depicted in Fig. 8. The obtained bestcompromised solution using the fuzzy min-max approach has the TOC of $1874.02 \$ / h$ and system power losses of 2.26 MW. The opened lines after the ONR/FRC are line 7 (connected between buses 5 and 8), line 9 (connected between buses 5 and 9), and line 12 (connected between buses 6 and 11). Fig. 9 depicts the SLD of 17 bus DS after the ONR/FRC. 


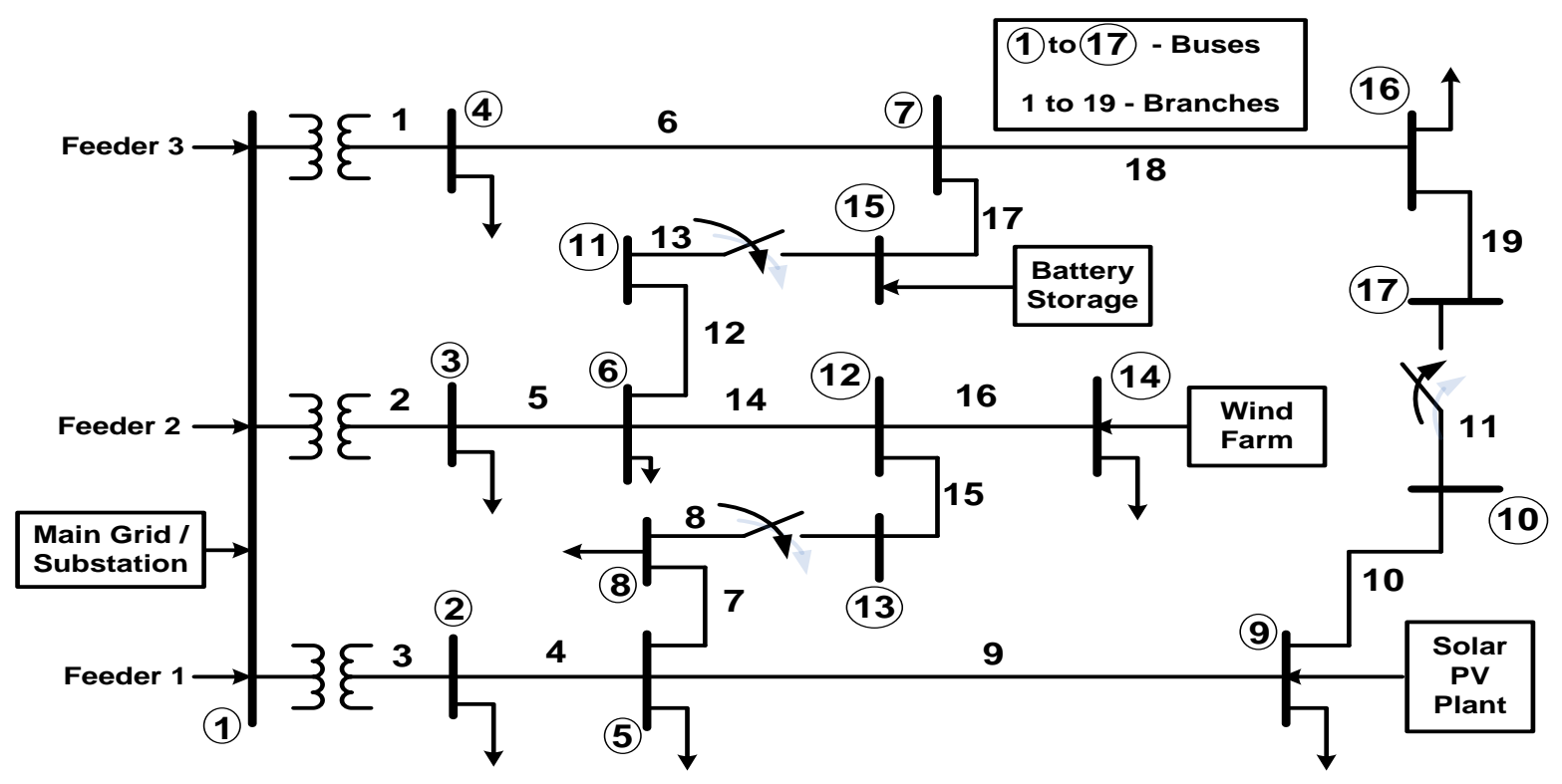

Fig. 7. SLD of 17 Bus Distribution System.

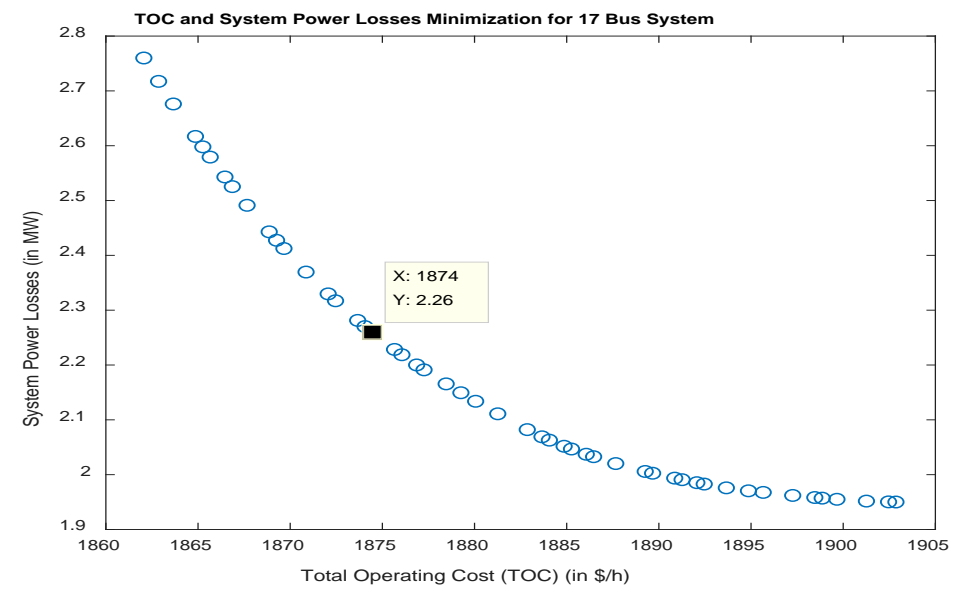

Fig. 8. Pareto Optimal Front / Set of TOC and System Power Losses for 17 Bus System.

TABLE II. OBJECTIVE FUNCTION VALUES FOR 17 BUS DS.

\begin{tabular}{|l|l|l|l|}
\hline \multirow{2}{*}{ Power outputs and objective function values } & \multicolumn{2}{|l|}{ Single objective-based ONR } & MOO based ONR \\
\cline { 2 - 5 } & TOC Minimization & Power loss Minimization & TOC and Power loss minimization \\
\hline Power output from feeders (MW) & 82.35 & 81.87 & 82.09 \\
\hline Power output from WEGs (MW) & 2.82 & 2.68 & 2.75 \\
\hline Power output from solar PV unit (MW) & 2.74 & 2.59 & 2.60 \\
\hline Power output from BES unit (MW) & 0.95 & 0.91 & 0.92 \\
\hline Total operating cost (TOC) (\$/h) & $\mathbf{1 8 6 2 . 0 6}$ & 1903.12 & $\mathbf{1 8 7 4 . 0 2}$ \\
\hline System power losses (MW) & 2.76 & $\mathbf{1 . 9 5}$ & $\mathbf{2 . 2 6}$ \\
\hline
\end{tabular}




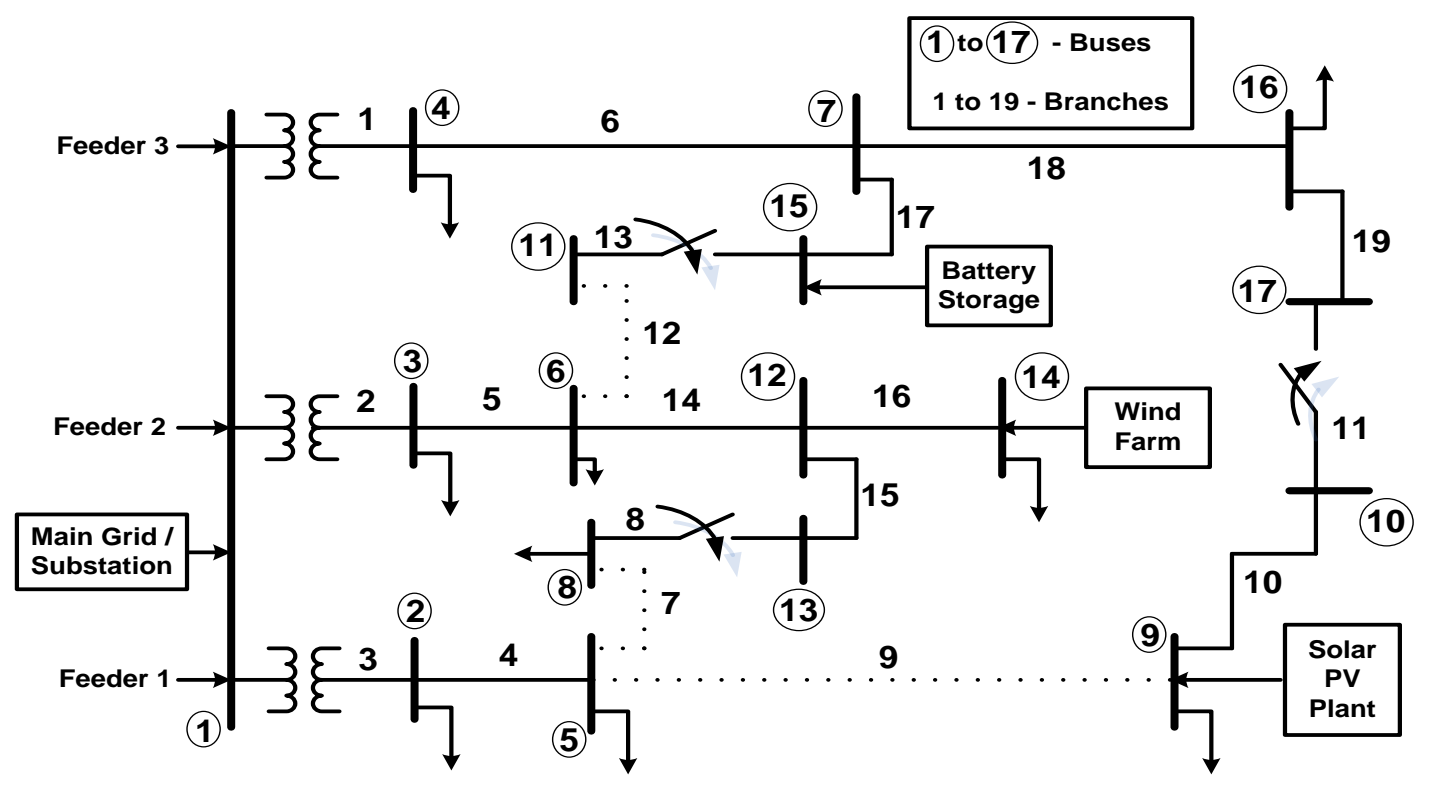

Fig. 9. SLD of 17 Bus Distribution System after ONR / FRC.

\section{CONCLUSIONS}

This paper proposes a multi-objective-based optimal network reconfiguration (ONR)/feeder reconfiguration (FRC) approach considering the multiple energy sources, and it has been solved by using the multi-objective crow search algorithm (MO-CSA). This ONR/FRC approach considers the total operating cost and system power losses minimization as objectives. Apart from the power received from the main grid, this paper considers the power from distributed generation (DG) such as wind energy generators (WEGs), solar PV units, and battery energy storage (BES) units. The stochastic nature of solar PV and wind power generation models is developed using the probabilistic approach in which the uncertainties associated with generation patterns have been modeled using the probability distribution functions. The proposed methodology has been implemented on two test systems, i.e., 14 bus and 17 bus distribution systems with 3 feeders.

\section{ACKNOWLEDGMENT}

This research work was funded by "Woosong University’s Academic Research Funding - 2021”.

\section{REFERENCES}

[1] S. Naveen, K. Sathish Kumar, K. Rajalakshmi, "Distribution system reconfiguration for loss minimization using modified bacterial foraging optimization algorithm," International Journal of Electrical Power \& Energy Systems, vol. 69, pp. 90-97, 2015.

[2] T.T. The, D.V. Ngoc, N.T. Anh, "Distribution Network Reconfiguration for Power Loss Reduction and Voltage Profile Improvement Using Chaotic Stochastic Fractal Search Algorithm,” Complexity, vol. 2020, pp. 1-15, 2020.

[3] C.T. Su, C.F. Chang, C.S. Lee, "Distribution Network Reconfiguration for Loss Reduction by Hybrid Differential Evolution", Electric Power Components and Systems, vol. 33, no. 12, pp. 1297-1312, 2005.

[4] A.O. Salau, Y.W. Gebru, D. Bitew, "Optimal network reconfiguration for power loss minimization and voltage profile enhancement in distribution systems," Heliyon, vol. 6, no. 6, 2020.

[5] I. Diaaeldin, S. Abdel Aleem, A. El-Rafei, A. Abdelaziz, A.F. Zobaa, "Optimal Network Reconfiguration in Active Distribution Networks with Soft Open Points and Distributed Generation,” Energies, vol. 12, 2019.

[6] W.T. Huang, T.H. Chen, H.T. Chen, J.S. Yang, K.L. Lian, Y.R. Chang, Y.D. Lee, Y.H. Ho, "A Two-stage Optimal Network Reconfiguration Approach for Minimizing Energy Loss of Distribution Networks Using Particle Swarm Optimization Algorithm” Energies, vol. 8, pp. 1389413910, 2015.

[7] A. Uniyal, S. Sarangi, "Optimal network reconfiguration and DG allocation using adaptive modified whale optimization algorithm considering probabilistic load flow," Electric Power Systems Research, vol. 192, 2021.

[8] A.J. Nowdeh, M. Babanezhad, S.A. Nowdeh, A. Naderipour, H. Kamyab, Z.A. Malek, V.K. Ramachandaramurthy, "Meta-heuristic matrix moth-flame algorithm for optimal reconfiguration of distribution networks and placement of solar and wind renewable sources considering reliability," Environmental Technology \& Innovation, vol. 20, 2020.

[9] M.I. Pathan, M. Al-Muhaini, S.Z. Djokic, "Optimal reconfiguration and supply restoration of distribution networks with hybrid microgrids," Electric Power Systems Research, vol. 187, 2020.

[10] M.A.T.G. Jahani, P. Nazarian, A. Safari, M.R. Haghifam, "Multiobjective optimization model for optimal reconfiguration of distribution networks with demand response services," Sustainable Cities and Society, vol. 47, 2019.

[11] I.B. Hamida, S.B. Salah, F. Msahli, M.F. Mimouni, “Optimal network reconfiguration and renewable DG integration considering time sequence variation in load and DGs," Renewable Energy, vol. 121, pp. 66-80, 2018.

[12] S. Essallah, A. Khedher, "Optimization of distribution system operation by network reconfiguration and DG integration using MPSO algorithm," Renewable Energy Focus, vol. 34, pp. 37-46, 2020.

[13] Y. Shang, "Resilient Multiscale Coordination Control against Adversarial Nodes”, Energies, vol. 11, no. 7, 2018.

[14] G. Chicco, A. Mazza, "Assessment of optimal distribution network reconfiguration results using stochastic dominance concepts," Sustainable Energy, Grids and Networks, vol. 9, pp. 75-79, 2017.

[15] S. Das, D. Das, A. Patra, "Reconfiguration of distribution networks with optimal placement of distributed generations in the presence of remote voltage controlled bus," Renewable and Sustainable Energy Reviews, vol. 73, pp. 772-781, 2017.

[16] S.S. Reddy, J.A. Momoh, "Realistic and Transparent Optimum Scheduling Strategy for Hybrid Power System”, IEEE Transactions on Smart Grid, vol. 6, no. 6, pp. 3114-3125, Nov. 2015. 
[17] S.S. Reddy, P.R. Bijwe, A.R. Abhyankar, "Joint Energy and Spinning Reserves Market Clearing for Wind-Thermal Power System Incorporating Wind Generation and Load Forecast Uncertainties”, IEEE Systems Journal, vol. 9, no. 1, pp. 152-164, Mar. 2015.

[18] S.S. Reddy, P.R. Bijwe, A.R. Abhyankar, "Real Time Economic Dispatch Considering Renewable Power Generation Variability and Uncertainty Over Scheduling Period”, IEEE Systems Journal, vol. 9, no. 4, pp. 1440-1451, Dec. 2015.

[19] S.S. Reddy, P.R. Bijwe, A.R. Abhyankar, "Optimum Day-Ahead Clearing of Energy and reserve Markets with Wind Power Generation using Anticipated Real-Time Adjustment Costs”, International Journal of Electrical Power \& Energy Systems, vol. 71, pp. 242-253, Oct. 2015.

[20] S.S. Reddy, "Day-ahead thermal and renewable power generation scheduling considering uncertainty”, Renewable Energy, vol. 131, pp. 956-965, Feb. 2019.

[21] D. Sudha Rani, N. Subrahmanyam, M. Sydulu, "Multi-Objective Invasive Weed Optimization - An application to optimal network reconfiguration in radial distribution systems," International Journal of Electrical Power \& Energy Systems, vol. 73, pp. 932-942, 2015.

[22] V. Rafi, P.K. Dhal, "Maximization savings in distribution networks with optimal location of type-I distributed generator along with reconfiguration using PSO-DA optimization techniques," Materials Today: Proceedings, vol. 33, no. 7, pp. 4094-4100, 2020.

[23] R. Fathi, B. Tousi, S. Galvani, "A new approach for optimal allocation of photovoltaic and wind clean energy resources in distribution networks with reconfiguration considering uncertainty based on info-gap decision theory with risk aversion strategy," Journal of Cleaner Production, vol. 295, 2021.

[24] R. Sanjay, T. Jayabarathi, T. Raghunathan, V. Ramesh, N. Mithulananthan, "Optimal allocation of distributed generation using hybrid grey wolf optimizer,” IEEE Access, vol. 5, pp. 14807-14818, 2017.

[25] A.M. Imran, M. Kowsalya, D.P. Kothari, “A novel integration technique for optimal network reconfiguration and distributed generation placement in power distribution networks," International Journal of Electrical Power \& Energy Systems, vol. 63, pp. 461-472, 2014.

[26] E. Kianmehr, S. Nikkhah, A. Rabiee, "Multi-objective stochastic model for joint optimal allocation of DG units and network reconfiguration from DG owner's and DisCo's perspectives,” Renewable Energy, vol. 132, pp. 471-485, 2019.

[27] A. Tiguercha, A.A. Ladjici, M. Boudour, "Optimal radial distribution network reconfiguration based on multi objective differential evolution algorithm,” IEEE Manchester PowerTech, Manchester, 2017, pp. 1-6.

[28] M. Buhari, V. Levi, A. Kapetanaki, "Cable Replacement Considering Optimal Wind Integration and Network Reconfiguration," IEEE Transactions on Smart Grid, vol. 9, no. 6, pp. 5752-5763, Nov. 2018.

[29] Y. Liu, J. Li, L. Wu, “Coordinated Optimal Network Reconfiguration and Voltage Regulator/DER Control for Unbalanced Distribution Systems," IEEE Transactions on Smart Grid, vol. 10, no. 3, pp. 29122922, May 2019.

[30] Y. Fu, H. Chiang, "Toward Optimal Multiperiod Network Reconfiguration for Increasing the Hosting Capacity of Distribution Networks," IEEE Transactions on Power Delivery, vol. 33, no. 5, pp. 2294-2304, Oct. 2018.

[31] T. Altun, R. Madani, A.P. Yadav, A. Nasir, A. Davoudi, "Optimal Reconfiguration of DC Networks," IEEE Transactions on Power Systems, vol. 35, no. 6, pp. 4272-4284, Nov. 2020.

[32] M.A. Samman, H. Mokhlis, N.N. Mansor, H. Mohamad, H. Suyono, N.M. Sapari, "Fast Optimal Network Reconfiguration With Guided Initialization Based on a Simplified Network Approach,” IEEE Access, vol. 8, pp. 11948-11963, 2020.

[33] C. Yong, X. Kong, Y. Chen, Zhijun E, K. Cui, X. Wang, "Multiobjective Scheduling of an Active Distribution Network Based on Coordinated Optimization of Source Network Load," Applied Sciences, vol. 8, 2018.

[34] A. Askarzadeh, "A novel meta-heuristic method for solving constrained engineering optimization problems: crow search algorithm”, Computers and Structures, vol. 169, pp. 1-12, 2016.

[35] P. Díaz, M.P. Cisneros, E. Cuevas, O. Avalos, J. Gálvez, S. Hinojosa, D. Zaldivar, "An Improved Crow Search Algorithm Applied to Energy Problems,” Energies, vol. 11, 2018.

[36] A.K. Pandey, S. Kirmani, "Multi-Objective Optimal Location and Sizing of Hybrid Photovoltaic System in Distribution Systems Using Crow Search Algorithm", International Journal of Renewable Energy Research, vol. 9, no.4, Dec. 2019. 